\title{
O CAPITAL ORIGINÁRIO DAS GRANDES EMPRESAS TÊXTEIS DE BLUMENAU E BRUSQUE
}

\author{
Vanessa Follmann Jurgenfeld' \\ Ana Lucia Gonçalves da Silva ${ }^{2}$
}

\section{Resumo}

As empresas têxteis de grande porte são importantes agentes na formação socioeconômica de Blumenau e Brusque, municípios localizados no Vale do Itajaí (SC). A análise sobre o capital originário, entendendo seus principais determinantes, revela o capital predominante na constituição desses grupos e permite melhor explicar suas origens e suas transformações mais recentes. Uma periodização histórica sugerida aqui identifica quatro grandes ciclos de acumulação deste capital, de 1880 até 1960.

Palavras-chave: grande empresa têxtil; Blumenau; Brusque

Classificação JEL: L67 e N9

\section{INTRODUÇÃO}

Os grandes grupos têxteis ${ }^{3}$ são parte essencial da formação socioeconômica $^{4}$ de Blumenau e Brusque, os mais populosos e mais antigos municípios do Vale do Itajaí (SC). Essa região começou a ser colonizada em 1850 e apenas 30 anos depois já iniciava a fabricação têxtil, tornando-se uma área de relevância deste ramo no país, de modo que hoje não é compreendida sem que se entenda este setor industrial.

Mestre em Desenvolvimento Economico pelo IE/UNICAMP. E-mail: vfollmann@hotmail.com

Doutora em Economia pelo IE/Unicamp. Professora-Doutora do IE/Unicamp. E-mail: neitp@eco.unicamp.br

São consideradas grandes empresas aquelas com 500 ou mais empregados.

4 A categoria "formação socioeconômica" é usada por outros autores. Ver: Furtado (1959), Rangel (I 987), Santos (2005). 
Além de representar o começo da produção de manufaturados no Vale do Itajaí e em Santa Catarina, o setor têxtil é representativo como forte empregador local, sendo agente ativo na dinâmica econômica dessa região. Constituído por quase 2 mil empresas e 50 mil trabalhadores, ele respondeu em 2010 por 4,7\% do emprego têxtil nacional, 3\% das empresas têxteis do país, $21,4 \%$ dos estabelecimentos têxteis do Estado de Santa Catarina

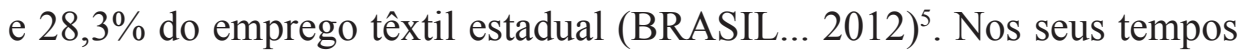
áureos, início dos anos 1980, por exemplo, chegava a representar mais de $60 \%$ dos empregos de Blumenau 6 .

Ainda que essa região seja mais conhecida hoje pelo grande número de pequenas e médias empresas, os grandes grupos têxteis possuem uma importância particular e histórica, por isso a pertinência de um estudo sobre eles. É na grande empresa têxtil ${ }^{7}$, segundo dados de 2010 , que estão concentrados $44 \%$ dos empregos têxteis de Blumenau e quase $20 \%$ dos empregos têxteis de Brusque (BRASIL... 2012). Além da sua representatividade em termos de emprego e renda, integrantes das famílias fundadoras de grandes grupos têxteis, como Hering e Renaux, possuem uma relevância política e social como membros de partidos políticos, como prefeitos ou na presidência de associações representativas de classe. Também foi das grandes têxteis que surgiu o capital para formação de diferentes setores industriais na região (alimentos, metalurgia e o próprio têxtil), bancos e empresa de geração de energia (serviços básicos).

A fim de entender como se constituiu esse capital originário, questionase neste artigo: quais frações de capital estiveram na formação desses grandes grupos e como determinantes histórico-geográficos e socioeconômicos estiveram vinculados ao surgimento dessas grandes empresas?

Há como parâmetro para a análise a ideia de que o capitalista que investe na produção não possui outra escolha a não ser crescer continuamente para sua própria sobrevivência no sistema e o que o move é a busca de lucro, de maneira sempre ampliada, em luta contra a tendência de decréscimo da

Outro dado importante é que o setor têxtil em 2010 era ainda o maior empregador entre 26 setores analisados em Blumenau (BRASIL... 20I2).

6 Em Blumenau, em 1958, o setor têxtil abrigava 66\% dos trabalhadores desta cidade. Em 1985, representava quase 40\% dos empregos gerados. Em 20 I0, 25\% (SINGER, 1968; BRASIL... 20I2).

7 A grande empresa representa menos de $1 \%$ dos estabelecimentos têxteis dessas duas cidades. Ver: Jurgenfeld (20|2). 
taxa de lucro, dada, ironicamente, pelo próprio movimento do capitalismo, mas recorrentemente contrarrestada. Na sua própria caminhada "evolutiva", observada basicamente pelos processos de concentração e centralização do capital, o sistema capitalista rompe sempre com qualquer tendência ao equilíbrio, impulsionando o processo de acumulação, ao mesmo tempo em que cria as bases para a sua própria destruição. A concentração seria o crescimento do capital por meio da capitalização da mais-valia produzida por esse mesmo capital. Já por centralização entende-se a reunião de diversos capitais em um só. Os dois processos, contudo, agem constantemente um sobre o outro.

Em busca de um lucro cada vez maior e em meio à concentração e à centralização, o capital se transforma. Ou melhor, as diversas frações (as diversas partes) que compõem o capital se transformam. Observar essas frações significa, portanto, entender o capital nas suas mais variadas apresentações (como, por exemplo, capital produtivo, mercantil-financeiro) ${ }^{8}$.

Diversos estudos ${ }^{9}$ já analisaram o setor têxtil e citaram as grandes empresas têxteis de Blumenau e Brusque, mas não as colocaram, com clareza, como o grande agente do capitalismo local, em uma análise que permitisse entender o tipo de capital dominante na origem dessas empresas

\footnotetext{
8 Cano (20 I 0) observa que o capital mercantil pode compreender as formas comercial e usurária. A origem deste capital é anterior à acumulação primitiva, que é a etapa do capitalismo originário. O capital mercantil inicia-se com as trocas mercantis de bens e serviços e estaria restrito à órbita da circulação. Com o avanço do capitalismo, sua forma inicial não desapareceria, mas, segundo este autor, algumas frações (do capital mercantil) se transformariam em três partes: I) em capital produtivo, ao penetrar a órbita da produção; 2) uma segunda parcela deste capital permaneceria como comercial - porém agora subordinada pelo novo, o capital industrial; 3) outras parcelas assumiriam o que Cano denominou de funções especializadas, como, por exemplo, a do capital imobiliário (CANO, 20 I 0). Segundo este mesmo autor, o capital mercantil será dominante em uma região nos primórdios de seu desenvolvimento capitalista. Depois, é "superado" pelo poder do capital industrial. Mas nunca perde de todo sua importância. O capital mercantil antigo reaparece em formas "modernizadas".

De acordo com Cano (20l0), "tomando algumas ilustrações históricas, podemos afirmar que muitas das antigas fortunas familiares, de proprietários de grandes fábricas têxteis (e também de alguns outros setores), em pleno período de industrialização, eram, na realidade, capitais mercantis que não se haviam convertidos plenamente em capitais industriais. Seus ativos - onde a terra urbana tinha alta participação - guardavam muito mais relação com o comportamento de um capital mercantil do que com o de um capital industrial. É preciso entender que, a despeito de ter se convertido em industrial, a mentalidade e cultura de seus titulares é ainda predominantemente mercantil: são comumente arcaicas suas ideias e reivindicações junto ao Estado, sobre temas como tarifas, tributação, contratos de trabalho, progresso técnico etc. [...] Assim, nossa história econômica mostra - até mesmo no Nordeste - várias conversões de capital mercantil arcaico em capital agrário, industrial (em geral nas indústrias leves e de menor porte), bancário (os antigos e pequenos bancos regionais privados) ou em serviços modernos. Ainda assim ele manterá seus condicionamentos sobre as estruturas de poder local" (CANO, 20 I 0, p. 6).

9 Ver, por exemplo: Mamigonian (1965); Hering (1987) e Filho (1995).
} 
e suas metamorfoses em uma linha histórica. Essa interpretação é importante por permitir, nos anos mais recentes, entender quais frações passam a dominar a empresa nesta etapa mais moderna do capitalismo (a partir da década de 1970), e quão diferentes podem (ou não) ser em relação à sua origem histórica.

Uma proposição que recaia sobre os determinantes sugere que o entendimento de uma realidade regional não se restringe à análise de seus fatores internos, mas também do seu confronto com fatores externos, contribuindo para desfazer a ideia de que somente uma endogenia local - como questões de conhecimento técnico prévio por parte dos imigrantes europeus, sobretudo, os alemães - tenha levado à região ao que hoje ela é.

Para a compreensão do processo de formação das grandes empresas, este artigo foi dividido em quatro partes, correspondentes aos grandes ciclos de acumulação deste capital: 1) De 1880 até a 1ª Guerra Mundial: este período representa o ciclo de expansão do capitalismo monopolista mundial a partir de 1880 (HILFERDING, 1910; HOBSON, 1908) e sua importância como emissor de imigrantes ao Vale do Itajaí. É o início do setor têxtil (e dos que seriam, no futuro, os grandes grupos) e da industrialização local. Trata-se de uma fase de predomínio do capital agrário e de nascimento do capital industrial regional; 2) Do fim da $1^{\text {a }}$ Guerra Mundial até a crise de 1929: período relacionado com o início da substituição de importação pelo país e aumento no número de imigrantes no Vale. Há novas empresas surgindo e uma fase de expansão do investimento das já instaladas com os lucros acumulados na $1^{\text {a }}$ Guerra. Estende-se até a crise de 1929, quando cessam tais desdobramentos; 3) Do fim da crise da Grande Depressão até a 2a Guerra Mundial: esta fase representa o fim da crise mundial de 1929. A indústria passa a ser o principal caminho para o crescimento do país. Novas empresas têxteis são constituídas nos anos 1930 em Blumenau e Brusque, principalmente a partir de 1933, quando a crise econômica diminui. É uma fase de consolidação do capital industrial têxtil na região e de nascimento do capital financeiro (bancos); 4) Do fim da $2^{\text {a }}$ Guerra Mundial até o fim da década de 1960: este período é marcado pelos impulsos dinâmicos da $2^{\text {a }}$ Guerra, pela implantação de um setor de bens de capital no país, por investimentos do Estado na industrialização pesada e maior integração entre as regiões brasileiras. Novas têxteis sur- 
gem no Vale do Itajaí. Depois de 1954, são mais exceção do que regra as empresas têxtil de grande porte nesta área ${ }^{10}$.

Obviamente, existem periodizações nacionais, como a feita por Mello (1982), e a específica sobre Santa Catarina, realizada por Goularti Filho (2002), a sobre industrialização do sul do Brasil, feita por Silva (2006), também utilizada, anteriormente, por Mamigonian (1960; 1965), e a de Stein (1957), para análise do setor têxtil nacional. Mas, ainda que bem expliquem seus objetos específicos - o Brasil, o Estado de Santa Catarina, a indústria na Região Sul do Brasil e o setor têxtil nacional, respectivamente -, não são suficientes para o tema central deste artigo, que são as empresas têxteis de grande porte de Blumenau e Brusque.

\section{A ORIGEM DO CAPITAL INDUSTRIAL TÊXTIL: DE 1880 ATÉ A $1^{\text {a }}$ GUERRA MUNDIAL}

Durante o século XIX e até o início do século XX, o território brasileiro poderia ser considerado um arquipélago, formado por ilhas que precariamente se conectavam via portos e ferrovias. Entre as regiões havia pouca relação do ponto de vista econômico ${ }^{11}$.

Os complexos regionais tinham sua própria economia, fato que era reforçado pela quase ausência de meios ágeis de comunicação terrestre. Assim, as indústrias mais expressivas de cada região sobreviveram sem a contestabilidade de demais concorrentes nacionais. Pertenciam, em sua maioria, à indústria leve, que é o caso do setor têxtil, que se instala no país nas últimas duas décadas do século XX (CANO, 1985).

O setor têxtil de Santa Catarina nascia em 1880, portanto, praticamente no mesmo momento do surgimento do setor têxtil nacional. A formação de empresas têxteis guarda relação com o estabelecimento do sistema colôniavenda $^{12}$ e com o empobrecimento do solo da região, depois de 20 a 30 anos

\footnotetext{
10 De acordo com dados da Rais/MTE (BRASIL... 20 I 2) sobre número de estabelecimentos têxteis com mais de 500 empregados, não há novas empresas de grande porte em Brusque nos anos mais recentes. Em 1990, este número totalizava quatro empresas, mesmo volume de 2010. Em 1985, dado mais antigo disponível, é possível observar que eram 5 empresas, portanto, ou houve fechamento de uma grande empresa ou essa grande empresa reduziu o número de empregados para menos de 500. Em Blumenau, também baseando-se em dados da Rais, há certa estabilidade nesse quadro: em 1985, havia II estabelecimentos têxteis com mais de 500 empregados. Ele passa para 9 em 1990, chega a 12 em 1995 e mantém-se em 12 em 2010.

Ver mais em Rangel (1987).

2 O sistema colônia-venda permitiu que recursos fossem acumulados por vendeiros e ajudou na associação de capitalistas locais em torno de diversas empresas. Ver: Mamigonian (1965) e Silva (2006).
} 
de rotação de culturas na pequena propriedade agrícola local, que guiou a busca de uma produção que tivesse alguma demanda e pouca oferta no mercado regional (MAMIGONIAN, 1965).

O capital industrial têxtil de Blumenau e Brusque não deriva do complexo cafeeiro, como se entende o início da industrialização de São Paulo (CANO, 1985; SILVA, 1973; MELLO, 1982). Mas observa-se que o têxtil regional, assim como o setor têxtil paulista, se desenvolveu em grande medida com auxílio do Estado. O período de nascedouro de diversas empresas desse ramo coincide com o momento em que o governo brasileiro concede, por exemplo, proteção tarifária, o que levou Stein (1957) a considerar de 1860 até 1930 os "anos dourados" do setor têxtil.

Até a $1^{\text {a }}$ Guerra Mundial, apesar do nascimento da indústria têxtil, ainda predominava na economia do Vale do Itajaí o capital agrário, principalmente relacionado à exploração da madeira. Era esse o principal núcleo de acumulação até as primeiras décadas do século XX (BOSSLE, 1988). A importância que a indústria têxtil ganhará ao longo do tempo está relacionada com a formação de um sistema de produção e de circulação, em que a separação entre o trabalhador e os meios de produção se explicita e se torna uma realidade técnica (e obviamente socioeconômica), principalmente após a $1^{\text {a }}$ Guerra Mundial. Ainda que o assalariamento ${ }^{13}$ em Blumenau surja antes das empresas têxteis, a indústria é, sobretudo, responsável por acentuar a divisão técnica e social do trabalho por ser a unidade de produção tipicamente capitalista.

O primeiro ciclo de formação das empresas têxteis em Blumenau e Brusque está explicitado no Quadro 1.

Quadro 1. Primeiro ciclo: os pioneiros têxteis de Blumenau e Brusque

\begin{tabular}{|l|l|l|}
\hline $\begin{array}{l}\text { Empresa/Ano } \\
\text { de Fundação/ } \\
\text { Localização }\end{array}$ & $\begin{array}{l}\text { Capital } \\
\text { fundador }\end{array}$ & Breve histórico \\
\hline $\begin{array}{l}\text { Hering/Blumenau } \\
(1880)\end{array}$ & COMERCIAL & $\begin{array}{l}\text { O imigrante Hermann Hering, com experiência } \\
\text { no ramo têxtil, depois de montar uma casa } \\
\text { comercial e um botequim trouxe sua família da } \\
\text { Alemanha e criou a Gebrüder Hering }\end{array}$ \\
\hline
\end{tabular}

13 Assalariamento em Blumenau surgiu nas primeiras obras da colonização. Dr. Blumenau contratava trabalhadores para abrir caminhos de terra e lhes pagava salários (DEEKE, 1917). 


\begin{tabular}{|c|c|c|}
\hline $\begin{array}{l}\text { Karsten/Blumenau } \\
(1882)\end{array}$ & $\begin{array}{l}\text { COMERCIAL; } \\
\text { POUPANÇA } \\
\text { INDIVIDUAL }\end{array}$ & $\begin{array}{l}\text { O imigrante alemão Johann Karsten, dono } \\
\text { de uma serraria, uniu-se ao imigrante alemão } \\
\text { Herinrich Hadlich e ao técnico da área têxtil } \\
\text { Gustav Roeder para montar a Tecelagem Roeder, } \\
\text { Karsten e Hadlich (mais tarde, Karsten) }\end{array}$ \\
\hline $\begin{array}{l}\text { Empresa Industrial } \\
\text { Garcia/Blumenau } \\
(1885)\end{array}$ & INDUSTRIAL & $\begin{array}{l}\text { A Garcia surge por iniciativa do imigrante } \\
\text { Gustav Roeder, que anteriormente havia criado a } \\
\text { Karsten com outros sócios }\end{array}$ \\
\hline $\begin{array}{l}\text { Fábrica de Tecidos } \\
\text { Carlos Renaux/ } \\
\text { Brusque (1892) }\end{array}$ & $\begin{array}{l}\text { AGRÍCOLA, } \\
\text { COMERCIAL }\end{array}$ & $\begin{array}{l}\text { A Renaux surge por iniciativa do imigrante } \\
\text { Carlos Renaux, que fora caixeiro em uma } \\
\text { casa comercial em Blumenau e depois partiu } \\
\text { para Brusque onde montou sua própria casa } \\
\text { comercial, em } 1890 \text {. Da casa comercial e da } \\
\text { associação com colonos agrícolas da região, } \\
\text { montou a empresa têxtil Renaux }\end{array}$ \\
\hline $\begin{array}{l}\text { Buettner/Brusque } \\
(1898)\end{array}$ & $\begin{array}{l}\text { COMERCIAL; } \\
\text { ARTESANAL }\end{array}$ & $\begin{array}{l}\text { Criada pelo imigrante alemão Eduardo von } \\
\text { Büettner. Antes de ir para o setor têxtil e } \\
\text { aproveitar-se do talento de familiares que faziam } \\
\text { bordados artesanalmente, ele criou uma casa de } \\
\text { secos e molhados, moagem de café e serrarias }\end{array}$ \\
\hline $\begin{array}{l}\text { Schlosser/Brusque } \\
(1911)\end{array}$ & $\begin{array}{l}\text { POUPANÇA } \\
\text { INDIVIDUAL; } \\
\text { AGRÍCOLA; } \\
\text { INDUSTRIAL; }\end{array}$ & $\begin{array}{l}\text { A empresa foi criada pelo imigrante alemão } \\
\text { Gustavo Schlösser, que trabalhara na fábrica } \\
\text { têxtil Renaux como operário. Em 1911, por meio } \\
\text { de recursos provenientes do trabalho, experiência } \\
\text { acumulada e ajuda de filhos, colonos e da } \\
\text { Renaux, fundou a firma G.Schlösser \& filhos }\end{array}$ \\
\hline
\end{tabular}

Fonte: Elaboração própria a partir de Broos \& Socorro (1980), Hering (1950), Hering (1987), Mamigonian (1965) e Seyferth (1974).

Há a seguinte linha do tempo: em Blumenau, surgiu primeiro a Hering, em 1880, pelo comerciante alemão Hermann Hering. Depois, em 1882, surgia a Karsten, pelas mãos do imigrante alemão Johann Karsten. Em 1885, foi a vez da criação da Empresa Industrial Garcia. Poucos anos depois, em Brusque, foi formada a Fábrica de Tecidos Carlos Renaux, criada em 1892 pelo imigrante alemão Carlos Renaux, e a Buettner, criada em 1898 pelo também imigrante alemão Edgard Von Buettner. Em 1911, nascia a Schlösser, em Brusque, por imigrantes poloneses. Esse grupo constituiu o primeiro ciclo de empresas têxteis no Vale do Itajaí, que se estende do fim do século XIX até a $1{ }^{\text {a }}$ Guerra Mundial (Quadro 1). 
A criação da grande empresa têxtil no Vale do Itajaí tem como base os industriais e recursos locais ${ }^{14}$ (MAMIGONIAN, 1965). Elas nasciam com pouco capital em espécie e com limitação de máquinas. Não utilizavam eletricidade (esta chegou à região em 1908), importavam da Alemanha máquinas usadas e insumos e, nesta primeira fase, vendiam os tecidos na região. Era comum começarem o processo industrial com um ou dois teares, como foi o caso da Teka, da Hering e da Buettner.

Conforme o Quadro 1, a origem do capital dessa indústria é bastante variada: há o capital comercial de donos de vendas (casas de exportação e importação), observa-se o capital de origem agrária advindo de colonos mais prósperos e também recursos provenientes de poupança acumulada na Alemanha, em pequena monta, por imigrantes. A falta de bancos neste início da indústria fazia com que os colonos oferecessem capital excedente da lavoura aos novos negócios. Havia empréstimo direto às empresas e os que depositavam recursos nas vendas e estas repassavam ao industrial (HERING, 1987).

Observa-se a importância do capital mercantil comercial que está na origem de diversas empresas. O Quadro 1 mostra que esteve na constituição de quatro das seis maiores empresas têxteis: Hering, Renaux, Buettner e Karsten. Ele, porém, associa-se a outros capitais, usando recursos emprestados de vários colonos agrícolas.

Hermann Hering, por exemplo, era imigrante da Saxônia, tendo chegado em 1870 com algum capital e algum conhecimento prévio de comércio e indústria. Tão logo definiu que havia possibilidade de um novo negócio em Blumenau, enviou carta a seu irmão Bruno para que viesse e trouxesse parte da família, que havia ficado na Saxônia. Hermann exerceu diversas funções antes da criação de uma manufatura, inclusive tendo aberto uma pequena casa comercial, que seria o principal capital para o início da empresa. A sua venda era no StadtPlatz ${ }^{15}$, hoje o que seria a principal rua de Blumenau, chamada XV de Novembro. Nos fundos deste comércio, foi instalado o primeiro tear, adquirido com as economias do patriarca (HERING, 1987).

14 Tais capitais possuíam uma ligação de cooperação. "Um número reduzido de sobrenomes se repete com prenomes diferentes nas diversas fases do desenvolvimento do município, que se confunde com as gerações de algumas famílias. Isto indica que a elite econômica blumenauense foi restritiva e pouco permeável ao ingresso de novos membros" (TOMIO, 2000, p. 77).

15 StadtPlatz significa, em alemão, área central. Essa localidade transformou-se no que é hoje o shopping Hering, no centro de Blumenau. 
Em pouco tempo, a empresa mudou-se para uma área própria, na zona rural, a três quilômetros do centro. A transferência permitiu a expansão física e uma aproximação aos trabalhadores rurais, que viriam a ser seus operários $^{16}$.

De 1880 a 1914, o crescimento da Hering resumia-se ao seu capital próprio, no qual estava originalmente o capital mercantil comercial, mas também a alguns empréstimos, como do próprio Dr. Blumenau ${ }^{17}$, que lhe emprestou recursos por ocasião da destruição causada pela enchente de 1880, recursos de colonos e também o feito pelo comerciante Ricardo Voigt (HERING, 1987). Pode-se, portanto, observar que o capital comercial representa em grande medida a origem deste grupo.

Em 1882, surgia a tecelagem Karsten. A família, composta por Johann Friedrich Christian Karsten, Maria Saps Karsten e seis filhos, teria imigrado da Alemanha inicialmente para o Rio de Janeiro, como convidada do imperador para administração de uma fazenda de café, o que durou apenas um ano. Depois, mudou-se para Blumenau. O primogênito Johann Karsten é quem teria dado início ao processo manufatureiro. Ele herdou do pai terras em Blumenau, que dedicava à agricultura, tendo instalado neste local um moinho de fubá movido por roda d'água. Em seguida, em 1869, anexou uma serraria ao negócio, mas perdeu seu patrimônio com a grande enchente, em 1880. Com a ajuda de amigos e pessoas da região, recuperou tudo (KARSTEN, 2014).

Houve então a criação da Tecelagem Roeder, Karsten \& Hadlich, com os sócios Herinrich Hadlich (pequeno comerciante) e Gustav Roeder, técnico têxtil, ambos também imigrantes alemães. A tecelagem iniciou suas atividades com teares adquiridos na Alemanha e uma pequena fiação. Hering (1987) relata que houve empréstimo de capital de colonos. Portanto, foi fundamental a atividade comercial e agrícola na sua origem. Em 1885 e 1886, Roeder e Hadlich retiraram-se da sociedade e Johann Karsten deu continuidade aos negócios.

A saída de Roeder representou a criação de uma outra empresa têxtil, como derivação do capital da Karsten, e a primeira relação observada de capital industrial têxtil criando um novo negócio têxtil na região. De

16 O "colono-operário" trabalha parte do tempo na empresa e parte na sua lavoura (HERING, 1987).

17 Dr. Blumenau foi o colonizador local. Ver: Deeke (1917). 
fato, Gustav Roeder fundou em 1885 a tecelagem que, depois de diversas alterações de razão social, chegou à Empresa Industrial Garcia (HERING, 1950). Roeder associou-se também ao antigo cervejeiro H. F. Schmidt (DEEKE, 1917).

A Garcia começou a operar com apenas três teares. Em 1889, Roeder a vendeu a um comerciante de Itajaí: Nicolau Malburg. Depois, a empresa foi novamente vendida para comerciantes locais: H. Probst, Luís Sachtleben e F. Busch (HERING, 1987). Na Garcia, portanto, também fica evidente a multiplicidade de capitais e a importância do capital comercial e do capital industrial da Karsten.

A realidade de Brusque não foi muito diferente do processo histórico de Blumenau. Dentre as iniciativas que "vingaram" em termos de manufatura têxtil em Brusque, esteve primeiramente a empresa de Renaux, imigrante alemão que teria chegado a Brusque em 1882, encarregado da gerência da filial de uma casa comercial em Blumenau. Renaux tinha estudo de "nível médio", tendo "trazido ao Brasil diploma e certificado de que trabalhara no banco de sua cidade natal" (HERING, 1987, p. 111). Depois de ser acolhido pelos comerciantes locais, que lhe deram trabalho, ele criou sua própria venda em Brusque e daí derivou o capital para uma manufatura ${ }^{18}$.

A Fábrica de Tecidos Carlos Renaux começou com vários sócios. Constam como sócios iniciais no negócio um agricultor de Brusque, de nome Augusto Klappoth, e Paulo Hoepcke ${ }^{19}$, comerciante no Desterro que, após a morte de Augusto Klappoth, assumiu o capital deste. Outros moradores do interior do município de sobrenome Wilke, Yeske, Klahn, Willrich, Haffermann também fizeram parte da sociedade, fornecendo pedras e madeira para a construção da fábrica (HERING, 1987).

A segunda manufatura têxtil de Brusque foi uma empresa de bordados finos, a Buettner, que durante algum tempo manteve em paralelo aos negócios têxteis o beneficiamento de produtos coloniais (álcool, arroz e café). Ela surgiu em 1898, também fundada por um vendeiro, cujo filho Eduardo Von Buettner tinha aprendido a técnica de bordados na Alemanha (SEYFERTH, 1974). A sua origem, contudo, guarda relação com a produção artesanal de

\footnotetext{
18 grupo Renaux, contudo, não era apenas voltado ao setor têxtil. Ele também possuía fecularia e continuou atuando com lojas comerciais na região (MAMIGONIAN, 1960).

19 Hoepcke tornou-se um dos maiores grupos empresariais de Santa Catarina, atuando em diferentes áreas.
} 
aventais e toalhas bordadas pela mulher e pela nora do comerciante, cujo trabalho teria sido motivador da ida do filho do fundador à Alemanha, para aprender sobre o assunto. A empresa, assim como as demais iniciativas no Vale do Itajaí, começou pequena: duas máquinas a pedal nas quais se confeccionava sombrinhas, aventais, cortinas, mosquiteiros e pano de bordar (HERING, 1987). Nota-se na origem da Buettner, portanto, a importância do capital agrícola, artesanal e comercial.

A terceira grande empresa têxtil a iniciar operações em Brusque foi a Schlösser. Ela foi fundada em 1911 por Gustavo Schlösser, um tecelão de Lodz (Polônia), e seus dois filhos, Hugo e Adolpho. O fundador chegou a Brusque em 1896 e teria sido contratado como técnico têxtil por Carlos Renaux, da Fábrica de Tecidos Carlos Renaux. Cerca de 15 anos depois, Gustavo Schlösser formou sua própria empresa, juntamente com seus filhos. O capital inicial era de 6 contos. A tecelagem iniciou com dois teares manuais e crédito concedido por Renaux (HERING, 1987).

A $1^{\text {a }}$ Guerra Mundial interrompeu o período de crescimento do setor têxtil nacional, de 1913 até 1915, e suspendeu por alguns anos o surgimento de novas empresas têxteis no Vale do Itajaí, mas não funcionou como limitador do crescimento do setor. Embora tenha dificultado a importação das matérias-primas e estrangulado o fluxo de capital ao país, por outro lado permitiu o avanço da produção têxtil nacional já existente por todo território, pela interrupção no fornecimento do produto importado (STEIN, 1957). O conflito foi especialmente positivo para empresas que conseguiram se preparar antes, com importação de maquinários ${ }^{20}$.

\subsection{A consolidação e as derivações do capital industrial têxtil para

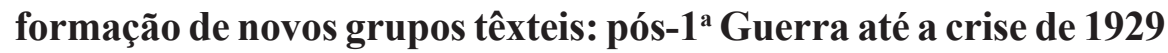

Depois de 1915, o setor têxtil brasileiro em geral ingressou em um novo período de crescimento que iria se prolongar até o final da década de vinte, quando eclodem os sinais da Grande Depressão de 1929 e que suspendem os investimentos em novas empresas têxteis em Blumenau e Brusque até 1935.

20 A Hering, por exemplo, importou uma fiação nova da Alemanha em 19।3, um pouco antes da eclosão do conflito (MAMIGONIAN, 1965). 
Havia, porém, um clima geral de prosperidade no país no começo dos anos vinte - tanto para as empresas têxteis como para o café - e, com a volta das importações de máquinas têxteis, após sua suspensão por ocasião da $1{ }^{a}$ Guerra, essa indústria retomava projetos de expansão (STEIN, 1957) ${ }^{21}$.

São desse período as empresas Altenburg; Haco; Fábrica de Chapéus Clesen \& Weege; Malhas Thiemann; Indústrias Renaux; Mafisa e Teka (Quadro 2).

A partir do fim da $1^{\text {a }}$ Guerra Mundial e, sobretudo durante a década de 1920, é o período em que a indústria têxtil assume papel significativo no interior da economia estadual. Esta década resultou em um novo ciclo de investimentos que se estende pelo menos até 1929.

Conforme Quadro 2, os novos investimentos provêm tanto daqueles que já possuíam algum conhecimento do ramo como daqueles que decidiram arriscar as suas primeiras investidas em um setor que começava a crescer.

Quadro 2. Segundo ciclo: as empresas têxteis de Blumenau e Brusque criadas na década de 1920

\begin{tabular}{|l|l|l|}
\hline \multicolumn{1}{|c|}{ Empresa } & Capital fundador & \multicolumn{1}{c|}{ Breve histórico } \\
\hline $\begin{array}{l}\text { Fábrica de } \\
\text { Acolchoados } \\
\text { Altenburg/ } \\
\text { Blumenau (1922) }\end{array}$ & ARTESANATO & $\begin{array}{l}\text { A imigrante alemã Johanna Altenburg fazia } \\
\text { artesanalmente acolchoados até criar a empresa } \\
\text { Altenburg }\end{array}$ \\
\hline $\begin{array}{l}\text { Fábrica de Chapéus } \\
\text { Clesen \& Weege/ } \\
\text { Blumenau (1925) }\end{array}$ & INDUSTRIAL & $\begin{array}{l}\text { A fábrica de chapéus surge por iniciativa de } \\
\text { Hermann Weege, nascido em Blumenau, e que } \\
\text { já tinha criado uma indústria de laticínios }\end{array}$ \\
\hline $\begin{array}{l}\text { Indústrias Renaux } \\
\text { S.A./Brusque } \\
\text { (1925) }\end{array}$ & INDUSTRIAL & $\begin{array}{l}\text { A empresa surge como desdobramento do } \\
\text { capital da Fábrica de Tecidos Carlos Renaux, } \\
\text { quando seu fundador decide dividir as } \\
\text { operações em empresas diferentes. Em anos } \\
\text { mais recentes, essa empresa será chamada } \\
\text { Renauxview }\end{array}$ \\
\hline
\end{tabular}

${ }^{21}$ Dentre os elementos que também contribuíam para a expansão mais geral do setor têxtil brasileiro, Stein (1957) destaca que parcela considerável da renda gerada pelas exportações de café disseminou-se, sob a forma de salários, criando um maior mercado consumidor. 


\begin{tabular}{|c|c|c|}
\hline $\begin{array}{l}\text { Teka/Blumenau } \\
\text { (1926) }\end{array}$ & $\begin{array}{l}\text { POUPANÇA } \\
\text { INDIVIDUAL, } \\
\text { AGRÍCOLA }\end{array}$ & $\begin{array}{l}\text { O imigrante alemão Paul Fritz Kuehnrich } \\
\text { chegou a Blumenau em } 1924 \text { e foi trabalhar } \\
\text { em uma olaria da família Haertel. Casou-se } \\
\text { com a filha do dono, chamada Marta, e com } \\
\text { ela iniciou confecção na própria residência. } \\
\text { Conseguiu recursos com vários colonos } \\
\text { para iniciar o negócio da Teka. No começo, } \\
\text { produzia acolchoados e camisaria }\end{array}$ \\
\hline $\begin{array}{l}\text { Indústria de Malhas } \\
\text { Thiemann/ } \\
\text { Blumenau (1927) }\end{array}$ & $\begin{array}{l}\text { POUPANÇA } \\
\text { INDIVIDUAL }\end{array}$ & $\begin{array}{l}\text { A firma foi criada por J. Thielmann, ex-oficial } \\
\text { do exército alemão, que aprendeu tecelagem } \\
\text { com leituras técnicas e abriu a pequena } \\
\text { empresa com sua esposa }\end{array}$ \\
\hline $\begin{array}{l}\text { Fábrica de } \\
\text { Bordados e } \\
\text { Cadarço Haco/ } \\
\text { Blumenau (1928) }\end{array}$ & INDUSTRIAL & $\begin{array}{l}\text { A família Conrad veio da Europa com alguns } \\
\text { recursos e logo adquiriu uma pequena empresa } \\
\text { de cadarços, a Haco. O fundador, Heinz } \\
\text { Conrad, era fabricante de sabonetes e perfumes } \\
\text { na Silésia. Comprou a fábrica de cadarços de } \\
\text { um blumenauense que havia visitado a Silésia }\end{array}$ \\
\hline $\begin{array}{l}\text { Malharia } \\
\text { Blumenau/ } \\
\text { Blumenau (1929) }\end{array}$ & INDUSTRIAL & $\begin{array}{l}\text { Dois netos do fundador da Hering, Ralph } \\
\text { Gross e Ulrich Steinbach, fundaram essa } \\
\text { empresa com apoio financeiro da Hering. } \\
\text { Introduziram a malharia fina do tipo jérsei e } \\
\text { charmeuse a partir da criação da Mafisa }\end{array}$ \\
\hline
\end{tabular}

Fonte: Elaboração própria a partir de Bossle (1988), Hering (1950), Hering (1987), Kuehnrich (1995), Mamigonian (1965) e Seyferth (1974).

Dentre os exemplos daqueles que começam a investir no ramo estão Hermann Weege ${ }^{22}$, que era do setor de laticínios em Blumenau, onde chegou em 1868. Ele investiu, em 1925, na fábrica de chapéus Klasen \& Weege, juntamente com dois sócios: Starretz e R. Klasen. Este último era dono de uma fundição. Já Starretz era diretor de uma empresa química alemã e teria trazido a ideia de montar tal fábrica da Alemanha, atuando posteriormente no fornecimento de tintas para os chapéus. Depois de alguns anos, quando nova diretoria assumiu, a empresa passou a denominar-se Fábrica de Chapéus Nelsa. Em 1930, essa fábrica passou para as mãos da filha de Weege, Cecília, cuja mãe - Paulina Karsten - era uma das filhas do fundador da

22 A família Weege será conhecida, nos anos 1960, pela fundação da empresa têxtil Malwee, que se localizará em Jaraguá do Sul. 
Karsten. Cecília ampliou as atividades, juntamente com seu marido, e criou uma malharia, a Maju Indústria Têxtil Ltda (HERING, 2002).

Outro exemplo é o de um ex-oficial do exército alemão chamado J. Thiemann, que também se "aventurou" no setor e criou a Fábrica de Malhas Thiemann S/A, depois que aprendeu tecelagem por meio de leituras técnicas.

Nos anos 1920, também foi criada a Fábrica de Cadarços e Bordados Haco S/A, cujos negócios foram adquiridos logo em seguida pela família Conrad (Johanna e Henrich Conrad e seu filho Carl Heinz Conrad), que era fabricante de sabonetes e perfumes na Europa. No início, a empresa produzia apenas cadarços de algodão em um rancho de madeira e em teares convencionais. "A fábrica foi adquirida pela família Conrad, em 1928, quando Johanna Conrad veio ao Brasil visitar o irmão Karl Hanke, exportador de madeira no norte de Santa Catarina" (HACO... 2003, s.n.).

Outra empresa que surge por iniciativa de pessoas de fora do ramo foi a Tecelagem Kuehnrich (Teka), fundada por Paul Fritz Kuehnrich. Os Kuehnrich imigraram em família. Paul Fritz, o filho caçula, foi, no entanto, o único membro que permaneceu em Blumenau e iniciou os negócios. Ele começou a trabalhar como ajudante em uma venda da família Volkert, quando, segundo Kuehnrich (1995), em 1926 lhe ofereceram uma fábrica de acolchoados, que consistia de uma máquina de preparar mantas, uma de costura de matelassê e duas de costura reta. Em 1928, a fábrica passou a produzir camisas e tinha 18 empregados (TEKA... s.d.).

Duas outras empresas deste segundo ciclo são Altenburg, originária de capital artesanal principalmente, e a Indústrias Renaux, que foi uma divisão da Fábrica de Tecidos Carlos Renaux, sendo constituída, portanto, por uma derivação de capital industrial (Quadro 2). Criada em 1925, a Indústrias Renaux era uma empresa voltada, especialmente, para tecidos decorativos, uma tecelagem artística, fornecendo tecidos para cortinas, pano para estofamento de móveis que até então eram artigos importados. Entrou em um nicho enquanto a Fábrica de Tecidos Carlos Renaux produzia tecidos diversos. Juridicamente, a Fábrica de Tecidos Carlos Renaux e a Indústrias Renaux eram empresas independentes, mas a administração de ambas era compartilhada.

Mais tarde, em 1929, em Blumenau surgiria um outro novo negócio no ramo têxtil, que futuramente se tornaria uma grande empresa. Como inicia- 
tiva de pessoas que já estavam no setor, a Malharia de Artefatos Finos S/A nasceu com sete operários e dois teares. Anos depois, se chamaria Malharia Blumenau (Mafisa). Dentre os sócios havia netos de Hermann Hering e a própria Cia Hering ${ }^{23}$.

Observam-se no Brasil os primeiros indícios da Grande Depressão em 1926, com a queda dos preços das mercadorias em razão da crise de superprodução mundial. A situação levou à falência algumas têxteis do Sudeste, mais sujeitas diretamente à crise do café pela proximidade com o cultivo deste grão. Alguns de seus concorrentes acabaram comprando equipamentos derivados dessas falências. Isso teria favorecido as empresas do "interior" do país, que compravam equipamentos do Rio de Janeiro e São Paulo. Uma das empresas que foram comprar bens de capital e instalações em São Paulo foi a Hering, colocando-os em operação em 1943, sob o nome de Meias Hering.

\section{2. $O 3^{\circ}$ ciclo têxtil e o capital industrial têxtil na formação de outros setores: do fim da Grande Depressão à $2^{\mathrm{a}}$ Guerra Mundial}

O período que se estende do fim da Grande Depressão até a $2^{\text {a }}$ Guerra Mundial é marcado pela derivação do capital industrial para outros ramos e um novo ciclo de acumulação das empresas têxteis de Blumenau e Brusque.

A década de 1920, em todo o país, constituiu a transição para o surgimento de uma formação industrial mais ampla, a industrialização "restringida"24, que nasceria a partir da recuperação da crise de 1929 e se estenderia a $1955 . \mathrm{Na}$

23 Outras empresas nasceram na década de 1920 e duas delas costumam levar a alguma confusão por receberem o nome Hering, caso da Fábrica de Gaitas Alfredo Hering e a Cristais Hering. Facilmente são associadas à empresa Hering, por isso faz-se necessária a observação de que em 1923 surgia a Fábrica de Gaitas Alfredo Hering, mas o surgimento desta empresa não tinha a ver com capital da Cia Hering. Alfredo era neto de Hermann Hering e trabalhava de mecânico na estrada de ferro em Blumenau. Seu estímulo para criar a fábrica veio de seu sogro, que era representante das gaitas de boca Hohner, produzidas na Alemanha. Com a morte de Alfredo, sua esposa Alice Husadel Hering deu continuidade aos negócios e investiu parte do capital em uma fábrica de cristais, a Fábrica de Cristais Hering, à qual foi anexada uma indústria de brinquedos (HERING, 1987). Mais recentemente, a Cristais Hering, por ocasião de seu fechamento, teve sua marca adquirida pela têxtil Hering.

Houve ainda derivações do capital têxtil relacionado com a Cia Hering para outros segmentos já na década de 1920. Em 1924, por exemplo, foi fundada a Fábrica de Chocolates Saturno, que em 1928 foi adquirida por Max Hering. Em 1928, foi criada pela família Hering a Indústria de Chocolates Sander S/A.

24 Baseado em Mello (1982), Cano destaca que: "só a partir de 1933, quando a economia nacional se recupera da crise e o movimento de acumulação industrial é o motor determinante da economia, é que se pode falar de industrialização. A rigor, de 1933 a 1955, ela será uma industrialização restringida, dada a incipiente produção nacional de bens de produção e a continuidade, em grande parte, da dependência do setor primário-exportador em determinar a capacidade para importar aqueles bens. De 1956 em diante, com a implantação de alguns setores industriais pesados (de consumo durável, intermediários e de capital) se alteraria o padrão de acumulação" (CANO, 1985, p. 52-53). 
década de 1930, destaca-se especialmente a mudança do papel do Estado ${ }^{25}$. O isolamento relativo das várias regiões brasileiras também começava a mudar. A Revolução de 1930, que colocou Getúlio Vargas no poder, daria início a um período de integração nacional. Em termos logísticos, há uma opção pelas rodovias e aumento gradativo das inter-relações entre regiões.

No período 1929-1933, sobretudo, altera-se o caráter principal do antigo padrão de acumulação brasileiro, dado pelo modelo primário-exportador, e a partir de então seria a indústria o principal determinante do nível de atividade de todo o país.

As empresas do Vale do Itajaí aproveitam-se disso e gradativamente avançam para o Sudeste. Essa situação é diferente do vivido até os anos 1930, quando a estrutura industrial regional se desenvolvia baseada em recursos acumulados localmente, com relativa independência do processo de acumulação que vinha tendo lugar em nível nacional (THEIS, 2000).

Ao mesmo tempo, o setor têxtil do Vale do Itajaí investia os lucros acumulados em outros segmentos. Os dois principais agentes do capital industrial na criação de novos capitais industriais nesta fase foram Hering e Fábrica de Tecidos Carlos Renaux. Do capital da Hering e da Renaux, nasceram empresas de energia, aço e cimento.

Mesmo com algum capital fluindo para outros setores, o têxtil continuaria, no entanto, predominante na economia local, com novas empresas surgindo (Quadro 3) em um terceiro grande ciclo de acumulação.

Quadro 3. O terceiro ciclo: as têxteis dos anos 1930

\begin{tabular}{|l|l|l|}
\hline $\begin{array}{c}\text { Empresa/Ano de } \\
\text { fundação/Localização }\end{array}$ & Capital fundador & \multicolumn{1}{c|}{ Breve histórico } \\
\hline $\begin{array}{l}\text { Cremer/Blumenau } \\
(1935)\end{array}$ & $\begin{array}{l}\text { INDUSTRIAL; } \\
\text { COMERCIAL; } \\
\text { POUPANÇA } \\
\text { INDIVIDUAL }\end{array}$ & $\begin{array}{l}\text { Criada por um imigrante alemão chamado } \\
\text { W.Cremer (representante comercial de uma } \\
\text { fábrica alemã de gazes medicinais) que se } \\
\text { associou a Alwin Schrader (comerciante) } \\
\text { e a Victor Hering (industrial) para formar o } \\
\text { capital inicial da empresa }\end{array}$ \\
\hline
\end{tabular}

25 O Estado passava por reformulações. Por um lado, aumentavam as pressões setoriais pela presença cada vez maior de novas frações da classe dominante. Por outro, a expansão do mercado de trabalho acelerava o preparo institucional da economia para que pudesse se defrontar com as reivindicações da crescente classe operária. Além disso, houve uma mudança na estrutura tributária do país: o imposto sobre o consumo, que no início do século perfazia pouco mais de dez por cento da arrecadação federal, ao final da década de 1920 perfazia mais de um quarto (CANO, 1985). 


\begin{tabular}{|l|l|l|}
\hline $\begin{array}{l}\text { Artex/Blumenau } \\
(1936)\end{array}$ & $\begin{array}{l}\text { COMERCIAL; } \\
\text { POUPANÇA } \\
\text { INDIVIDUAL }\end{array}$ & $\begin{array}{l}\text { Surgiu por união do capital de Ricardo } \\
\text { Peiter (comerciante de Brusque) com o de } \\
\text { Teófilo Zadrosny (representante de firmas } \\
\text { comerciais) e o de O. Huber (mestre- } \\
\text { tecelão da Empresa Industrial Garcia) }\end{array}$ \\
\hline $\begin{array}{l}\text { Indústria de Linhas } \\
\text { Leopoldo Schmalz/ } \\
\text { Gaspar (1938) }\end{array}$ & $\begin{array}{l}\text { COMERCIAL; } \\
\text { INDUSTRIAL }\end{array}$ & $\begin{array}{l}\text { Schramm (comerciante local), Willy } \\
\text { Schossland (comerciante de São Francisco } \\
\text { do Sul) e Leopoldo Schmalz (industrial em } \\
\text { São Paulo), cunhado de ambos }\end{array}$ \\
\hline
\end{tabular}

Fonte: Elaboração própria a partir de Bossle (1988), Hering (1950), Hering (1987), Mamigonian (1965) e Seyferth (1974)

Conforme o Quadro 3, a segunda metade da década de 1930 foi o período de constituição de duas empresas importantes do ramo têxtil em Blumenau: a Cremer e a Artex. Além disso, em $\operatorname{Gaspar}^{26}$, houve, em 1938, a fundação da Indústria de Linhas Leopoldo Schmalz, que mais tarde se chamaria Linhas Círculo.

A formação da Cremer guarda relação com o comerciante Alwin Schrader. Terceiro filho de um imigrante alemão, ele herdou uma casa comercial chamada "Casa Comercial Schrader". Em 1923, Schrader assumiu a gerência da Empresa Industrial Garcia, na qual permaneceu até 1931, e lá conheceu o imigrante alemão Werner Cremer, conhecedor das técnicas de criação de materiais curativos, com quem se associou em 1935. Na obra de Hering (1950) consta que a Hering também virou sócia do novo negócio.

Um ano depois, em 1936, surgia outra têxtil, a Artex. Essa empresa é fruto de um mestre-tecelão que trabalhava na Empresa Industrial Garcia, Otto Huber, que se associou a Teófilo Zadrosny, representante de firmas comerciais em Blumenau, e a Ricardo Peiter, comerciante local. O capital inicial da Artex foi conseguido com 17 sócios, todos do meio comercial e industrial do Vale do Itajaí.

Quase no mesmo momento, em 1938, nascia a fábrica de linhas Leopoldo Schmalz, na cidade de Gaspar. Ela resulta de uma sociedade entre Júlio Schramm (comerciante local), Willy Schossland (comerciante de São

26 Gaspar era parte de Blumenau, mas foi desmembrado em março de 1934. Conforme Tomio (2000), o período de 1924 a 1937 marca a redução do território de Blumenau com a criação não só do município de Gaspar, mas também de Rio do Sul, Indaial, Timbó e Ibirama. Posteriormente, ainda seriam desmembrados o atual município de Pomerode e o de Massaranduba. 
Francisco do Sul) e Leopoldo Schmalz (industrial em São Paulo, nascido em Joinville), cunhado de ambos (BOOS JR., s.d.).

Os avanços após 1930, e especialmente na década de 1940, têm a ver com o mercado do Sudeste, especificamente São Paulo, que, com a $2^{\text {a }}$ Guerra Mundial, e a consequente restrição de importações e aumento da integração nacional, se tornava a "locomotiva industrial" do país. "Minas Gerais, Santa Catarina, Rio de Janeiro e Guanabara receberam impactos positivos via complementaridade industrial ${ }^{27}$ num sentido amplo, isto é, não apenas pela oferta de bens de produção, mas também de consumo" ao Sudeste (CANO, 1985, p. 207-208).

Os anos 1930 também são caracterizados pelo avanço dessas empresas regionalmente para outras atividades, como o setor de madeira e o setor bancário ${ }^{28}$.

${ }^{27}$ Na visão de Cano, a integração nacional, considerando São Paulo o principal locus de reprodução do capital, proporcionou efeitos de estímulo, de inibição ou bloqueio e, até mesmo, de destruição. No caso de Santa Catarina e inclusive da têxtil catarinense, a integração teve mais a ver com efeitos de estímulo. Os efeitos de estímulo decorreram de: I) a demanda anteriormente satisfeita por importações do exterior que passa a ser cativa à indústria nacional; 2) a expansão da demanda urbana (regional e /ou nacional) que se dá pelo processo de recuperação e crescimento (CANO, 1985, p. 191).

${ }^{28}$ A exploração da madeira historicamente existiu desde o início da colonização do Vale do Itajaí. Ela guarda relação direta com a família Odebrecht, a partir de Emílio Odebrecht, engenheiro alemão contratado por Dr. Blumenau para medição de terras para divisão na região. Esse imigrante também foi responsável, anos mais tarde, pelo levantamento topográfico para linhas de comunicação em Blumenau. Mas foi seu filho, Rodolpho Odebrecht, quem de fato iniciou os negócios no ramo da madeira, quando criou uma fábrica de esquadrias para exportação, em Rio do Sul, cidade no Alto Vale do Itajaí, nos anos 1930. A Rodolpho Odebrecht logo se associaram empresários do setor têxtil, Max e Curt Hering. Poucos anos depois, houve a entrada de Otto Renaux, da Fábrica Renaux, nos negócios.

Durante a 2a Guerra Mundial, contudo, as reservas de madeira começaram a se esgotar no Vale do Itajaí. Com o fim das reservas, a atividade madeireira transferiu-se para Lages. Essa área, que era conhecida por sua reserva de araucárias, passou a ser explorada por um cultivo comercial da espécie pinus elliotti e pinus taeda, de alta produtividade. Nesta época, houve investimentos da Hering novamente no ramo, a fim de explorar a produção de papel, por meio da Companhia Fábrica de Papel de Itajaí (HERING, I950, p. 391). O ramo da madeira também acabou atraindo Irineu Bornhausen, que futuramente se tornaria governador de Santa Catarina. Ele se tornou sócio da empresa Gropp S/A, que foi fundada em Rio do Sul. Bornhausen associou-se com Otto Renaux. E dessa união também houve a ideia de criação de um banco catarinense, o Banco INCO (Banco Indústria e Comércio de Santa Catarina). O Banco INCO, contudo, não é o primeiro banco da região. O primeiro foi o Banco Nacional do Comércio de Porto Alegre. O Banco do Brasil só surge na região como emprestador de recursos após a 2a Guerra Mundial (MAMIGONIAN, 1965). O INCO tinha sede em Itajaí. Várias pessoas da área de comércio e transporte da região do Vale do Itajaí entraram no negócio criado por Renaux e Bornhausen (HERING, 1987). O Banco INCO representou a entrada do setor têxtil no ramo financeiro de maneira explícita. Ele também foi uma tentativa de preencher um vazio financeiro bancário (O BANCO... 1950). Em 1942, o banco comandava um início de processo de centralização financeira com a incorporação da Caixa Agrícola e Comercial de Blumenau, que em parte pertencia à empresa Hering. Do capital da Hering, em associação com o capital da Renaux, saíram recursos para a compra de parte das ações do Banco de Crédito Agrícola de Bella Aliança (em Rio do Sul), que também foi incorporado pelo INCO. Do capital da Hering também derivou parte do dinheiro para a criação do Banco Agrícola e Comercial de Blumenau, fundado em 1936, e incorporado pelo INCO em I942. Este banco já havia encampado a Caixa Agrícola, que havia sido fundada em 1907. O Banco INCO acabou incorporado em 1968 pelo Bradesco. 


\section{3. $\mathrm{O} 4^{\circ}$ ciclo têxtil e a expansão dos grandes grupos do Vale do Itajaí: do fim da $2^{\text {a }}$ Guerra Mundial até o fim dos anos 1960}

A $2^{\text {a }}$ Guerra Mundial, apesar de provocar um colapso nas importações, pode ser vista de um ponto mais positivo do que negativo no setor têxtil, especialmente, porque as economias regionais se integrarão mais ao mercado nacional e passarão a suprir outras regiões do país e do mundo via exportações, já que em 1941 os produtos europeus e japoneses desapareceram do mercado mundial. Os têxteis brasileiros entrarão a partir daí na América Latina, Europa e África do Sul (STEIN, 1957).

As têxteis do Vale do Itajaí neste momento começaram de fato a exportar e assumiram importante posição no Sudeste brasileiro. Além disso, aproveitaram para realizar aquisição de empresas ${ }^{29}$.

Conrad, da empresa Haco, teria usado os lucros acumulados durante o conflito para comprar quatro concorrentes: uma firma em Joinville (em 1942, a Haco adquiriu a empresa Fernandes, o que incluiu quatro teares convencionais para produção de etiquetas tecidas) e três outras concorrentes em São Paulo, transformando-se na maior empresa de etiquetas da América do Sul.

Em 1944, a Hering também adquiriu uma fábrica no Rio Grande do Sul que estava inativa e comprou a empresa dos Irmãos Eckardt, de pequeno porte, localizada em Indaial (SC), que fabricava malhas (BROOS, SOCORRO, 1980; HERING, 1987).

Após a $2^{\text {a }}$ Guerra Mundial, há uma nova série de mudanças estruturais importantes no Brasil e no mundo que afetarão o setor têxtil de Blumenau e Brusque.

O Estado-nação faz investimento em estatais de infraestrutura das mais diversas áreas e cria um setor de bens de capital que serve de alavanca para o desenvolvimento dos demais setores industriais. Deste período constam a criação de empresas siderúrgicas e mineradoras (CSN e Vale do Rio Doce), de petróleo (Petrobrás) e o avanço na área de transportes, com a criação de grandes eixos rodoviários, que reforçam o processo de concentração industrial em São Paulo (CANO, 1985).

\footnotetext{
Ressalta-se, porém, que nem tudo foi positivo durante a 2a Guerra Mundial para as têxteis do Vale do Itajaí. Segundo Hering ( 1987), a declaração de guerra entre o Brasil e o eixo Alemanha-Itália fez com que industriais e comerciantes de origem alemã fossem retirados de seus cargos por terem seus nomes em uma "lista negra". Após o conflito, contudo, eles voltaram a assumir a administração.
} 
Tavares (1998) entendeu este momento como o período de constituição de forças capitalistas de fato no país, pela criação de um setor de bens de capital, motor não só para si, como para os demais setores industriais.

Cano (1985) divide o período 1956-1970 em duas partes: 1956-1961 e 1962-1970. O primeiro subperíodo compreende a fase áurea de inversões decorrentes do Programa de Metas de Juscelino Kubstichek; o segundo, os anos da crise de 1962-1967.

Em termos nacionais, o enorme esforço de inversão a que foi submetido o país até 1961, devido à sua estreita base técnica industrial, ao desajuste entre oferta e demanda industriais, concomitantemente ao nível e à distribuição da renda e à deficiência do sistema financeiro, conduziriam a economia a uma crise de realização ${ }^{30}$ entre 1962 e 1967. A crise teve relação com a implantação de setores de ponta com grande capacidade ociosa, inflação e queda do gasto público. A sua superação teve a ver com a implantação de diferenciação de produtos para atingir camadas sociais de média e alta renda e foi devida também aos incentivos às exportações (CANO, 1985).

Em termos de formação de novo capital têxtil, no primeiro subperíodo definido por Cano, três grandes empresas têxteis nascerão no Vale do Itajaí: a Sul Fabril (1947), a Maju (1953) e a Dudalina (1954), conforme Quadro 4.

Quadro 4. O quarto ciclo: as empresas têxteis do pós-2a Guerra Mundial

\begin{tabular}{|l|l|l|}
\hline \multicolumn{1}{|c|}{ Empresa } & Capital fundador & \multicolumn{1}{c|}{ Breve histórico } \\
\hline $\begin{array}{l}\text { Sul Fabril/Blumenau } \\
(1947)\end{array}$ & $\begin{array}{l}\text { POUPANÇA } \\
\text { INDIVIDUAL }\end{array}$ & $\begin{array}{l}\text { Surgiu por iniciativa de dois empregados } \\
\text { (Paul Fritzche e Maurício da Graça) } \\
\text { da fábrica de camisas Rodolfo Kander, } \\
\text { localizada em Blumenau, que se } \\
\text { associaram para criar nova empresa de } \\
\text { vestuário na região }\end{array}$ \\
\hline $\begin{array}{l}\text { Maju Indústria Têxtil/ } \\
\text { Blumenau (1953) }\end{array}$ & INDUSTRIAL & $\begin{array}{l}\text { Surgiu do capital da Chapéus Nelsa, como } \\
\text { uma alternativa mais rentável de negócios } \\
\text { da família Weege }\end{array}$ \\
\hline
\end{tabular}

30 Importante ressaltar que o período inicial da crise coincidirá com o início do sistema de incentivos fiscais, especialmente para o desenvolvimento da região Nordeste, via SUDENE. Entre 1962 e 1967, tais incentivos foram ampliados a outras regiões como a Amazônia, com a instalação da Zona Franca de Manaus. 


\begin{tabular}{|l|l|l|}
\hline $\begin{array}{l}\text { Dudalina/Blumenau } \\
(1954)\end{array}$ & COMERCIAL & $\begin{array}{l}\text { Antes de criar a Dudalina, o casal Duda } \\
\text { e Adelina de Souza possuía um armazém } \\
\text { de secos e molhados, do qual derivou } \\
\text { recursos para iniciar a fábrica têxtil }\end{array}$ \\
\hline
\end{tabular}

Fonte: Elaboração própria a partir de Hering (2002); 50 Anos... (1997); Görgen (1993).

A fábrica de camisas Sul Fabril foi criada por dois então empregados da fábrica de camisas blumenauense, de médio porte, Rodolpho Kander: Paul Fritzche e Maurício Ramos da Graça. Esses dois sócios forneceram todo o capital inicial do negócio, que começou com produção de camisas (HERING, 1987). Os dez primeiros anos da Sul Fabril foram destinados à aquisição de imóveis, ampliação e renovação de máquinas, equipamentos e expansão do parque fabril.

Seis anos depois, nasceria a Maju. Esta empresa foi criada depois de uma viagem a Alemanha feita por Cecília Weege, que estava em busca de uma alternativa para os negócios de sua família, a fábrica de Chapéus Nelsa, em um contexto no qual a moda dos chapéus se enfraquecia. Assim, a Maju, derivada do capital industrial da Chapéus Nelsa, acabou se tornando o principal negócio da família, que em 1965 encerrou as atividades da empresa originária (HERING, 2002).

Em 1954, foi então criada outra empresa têxtil importante na região do Vale do Itajaí. Por iniciativa do casal Duda (Rodolfo Francisco de Souza Filho) e Adelina Souza foi fundada a Dudalina. O casal tinha um armazém de secos e molhados na cidade de Luis Alves, no Vale do Itajaí. Em uma ocasião, em São Paulo, Duda decidiu comprar tecido de seda para vender no armazém, mas não houve demanda, e então Adelina decidiu transformá -lo em camisas. (GÖRGEN, 1993). Portanto, é do capital comercial e da produção artesanal de camisas que se origina o grupo Dudalina.

Conforme é observado no Quadro 4, todas as empresas surgiram até 1954. No segundo subperíodo (1962-1970) definido por Cano (1985), portanto, não emergem novas empresas têxteis que se transformarão em empresas de grande porte nesses dois municípios. Em Brusque, será uma fase caracterizada principalmente pela pequena e média empresa, conforme constatou Mamigonian (1960). Serão empresas que dificilmente superam a marca de 100 operários cada uma. Muitas, inclusive, nasceram para produzir para as maiores. 
A partir principalmente da década de 1960, as modificações do capital industrial têxtil que podem ser observadas em Blumenau e Brusque dizem respeito a uma maior concentração e centralização de capital capitaneadas pela grande empresa já existente. Não há praticamente (com raras exceções) criação de nova empresa têxtil nesses municípios que se configurariam em um grande grupo têxtil de relevância nacional.

É importante observar que os anos 1960 em Santa Catarina é a fase do Plano de Metas do Governo (PLAMEG) ${ }^{31}$, criado em 1961, no Governo de Celso Ramos, que serviu de incentivo para o desenvolvimento industrial do Estado como um todo. Aliado a ele, criou-se o Banco de Desenvolvimento do Estado (BDE), que teria viabilizado os investimentos do PLAMEG I e II e o Banco Regional de Desenvolvimento do Extremo Sul (BRDE), que teria papel fundamental no desenvolvimento do setor industrial.

É curioso notar que há a partir deste momento também um novo eixo de crescimento industrial no Estado, dado essencialmente pela indústria metal-mecânica, sobretudo localizada em Joinville. Em termos nacionais, o foco do Estado também passa a ser o setor de bens de capital e um desenvolvimento a partir dos impulsos gerados por outros setores, como a indústria automobilística.

Também é interessante observar que justamente entre 1960 e 1970 há importante ruptura no capitalismo mundial, um período em que se observa a ascensão do capitalismo financeiro, que, por sua vez, muda a forma de operação das empresas, por impor um novo jogo de forças na competição agora em escala global.

\section{CONCLUSÃO}

É possível entender a origem e os desdobramentos de capital dos grandes grupos do setor têxtil do Vale do Itajaí dividindo-os em ciclos de acumulação. Tais ciclos estão inter-relacionados com os movimentos do capitalismo histórico mundial e cada ciclo expressa o predomínio de uma fração de capital (agrário, comercial, financeiro, industrial etc., inclusive o aporte de poupanças individuais trazidas em geral do exterior), ainda que as demais frações também estejam presentes.

31 Ver: Schmitz (1982). 
Observou-se que as empresas têxteis nasceram pequenas e com recursos provenientes de uma pluralidade de capitais, com destaque para recursos de colonos e de capital comercial, mas não restrito a isso. Do processo de acumulação do capital industrial têxtil há, em um primeiro momento, nascimento de outras empresas têxteis e, posteriormente, uma diversificação para outros setores industriais.

Essas derivações podem ser consideradas restritas (em sua grande maioria) a setores de baixa intensidade tecnológica, como o ramo de chocolates, agrário (madeira e celulose) e o próprio têxtil, além da incursão sem sucesso no setor financeiro (evidenciada pela venda do Banco Inco ao Bradesco nos anos 1960).

Em termos de criação de novas empresas, destaca-se o papel principalmente dos grupos Hering e Renaux. No entanto, é preciso lembrar que eles não deram um grande salto para setores que os colocassem em um nível muito elevado proporcionalmente de acumulação (alta tecnologia, por exemplo).

Observou-se que houve uma cooperação histórica entre a burguesia de Blumenau e região no processo de formação de outros grupos, iniciando a concentração e a centralização de capital. E após a $2^{\text {a }}$ Guerra Mundial, é possível notar que há um impulso definitivo para que os têxteis de Santa Catarina se tornassem grupos nacionais.

Após a década de 1960, não há criação de mais empresas têxteis no Vale do Itajaí que se tornarão grandes grupos de relevância nacional. Os anos 1950 foram os últimos fartos neste sentido. Após este período, nascem pequenas empresas que se tornam, no máximo, médias empresas. Pode-se melhor dizer que são raros e constituem mais exceção do que regra aquelas que conseguem chegar a ser grandes grupos de importância nacional. É, coincidentemente, entre meados dos anos 1960 e anos 1970 que ocorrerá uma ruptura no padrão de acumulação mundial (fim do padrão ouro-dólar), com transformações relevantes na economia mundial, no que diz respeito à competição internacional, operação de empresas transnacionais e um período em que se evidencia o pós-fordismo e o predomínio do capitalismo financeiro.

Fica claro que a dinâmica de acumulação do setor têxtil envolveu questões regionais específicas, mas que não estiveram alheias às determinações nacionais e externas. A formação de capital das grandes empresas têxteis de Blumenau e Brusque é base necessária para as interpretações do pós-1960 
e 1970, para entender sob quais condições esses grupos se inserem na nova dinâmica do capitalismo histórico mundial.

\section{FOUNDING CAPITAL OF LARGE TEXTILE COMPANIES OF BLUMENAU AND BRUSQUE}

\section{Abstract}

Large textile companies are important agents in the social economic formation of Blumenau and Brusque, cities located at the Vale do Itajaí (SC). An analysis about the former capital of these groups, understanding the most important elements for that, highlights the comprehension of the past and about the contemporary changes in those groups. This article has an historical periodization that identifies four accumulation cycles of this capital, from 1880 until 1960.

Keywords: Large textile companies; Blumenau; Brusque

\section{JEL Classification: L67 and N9}

\section{REFERÊNCIAS}

50 ANOS Sul Fabril. O Radar, órgão de comunicação e divulgação dos funcionários da Sul Fabril S/A, ano 33, n. 408, Fevereiro de 1997, [S.1: s.n.]. Não paginado.

BOOS JR., A. Linhas Círculo 60 anos. Revista comemorativa dos 60 anos da empresa. [S.1: s.n.], p. 13-59.

BOSSLE, O. História da industrialização catarinense: das origens à integração no desenvolvimento. Edição comemorativa: Confederação Nacional da Indústria (CNI) e Federação das Indústrias do Estado de Santa Catarina (Fiesc). Florianópolis, 1988. 
BRASIL. Ministério do Trabalho (MTE), Pesquisa de emprego e estabelecimentos Rais (Relação Anual de Informações Sociais) para os anos: 1985; 1990; 1995; 2000; 2005 e 2010. Disponível em: http://portal.mte.gov.br/ geral/estatisticas.htm. Acesso em 10 de janeiro de 2012.

BROOS, H.; SOCORRO, F. A Hering de Blumenau: um século (1880-1980). Blumenau, 1980.

CANO, W. Desequilíbrios Regionais e Concentração Industrial no Brasil (1930-1970). Global Editora. Campinas (SP), 1985.

Reflexões sobre o papel do capital mercantil na questão regional e urbana do Brasil. Texto para Discussão. IE/Unicamp, Campinas n. 177, maio de 2010.

DEEKE, J. (1917) O município de Blumenau e a história do seu desenvolvimento. Nova Letra Editoração e Impressão. Blumenau, 1995.

FURTADO, C. (1959). Formação econômica do Brasil. Biblioteca Universitária de Ciências Sociais. Série 2. Cia Editora Nacional, 32a edição, 2004.

GÖRGEN, J. Tesoura mágica. Revista Expressão. Ano III, n. 31, 1993, S.1, p. 55-58.

GOULARTI FILHO, A. (2002). Formação Econômica de Santa Catarina. Editora da UFSC, Florianópolis, 2007.

HACO comemora 75 anos de fundação. Informe comercial, jornal de Santa Catarina, 02 de maio de 2003, p. 2- 7.

HERING, I. Desenvolvimento da indústria blumenauense. In: Centenário de Blumenau, 1950.

HERING, M.L.R. Colonização e indústria no Vale do Itajaí: o modelo catarinense de desenvolvimento, 1987. 
História de vida Sra. Cecília Lischke. Blumenau em Cadernos. Tomo XLIII. N. 07/08. jul/ago 2002.

HILFERDING, R. (1910). O capital financeiro. Nova Cultural, São Paulo, 1985.

HOBSON, J.A. (1908). A Evolução do capitalismo moderno. Ed. Abril, SP, 1993.

JURGENFELD, V.F. Transformações dos Grandes Grupos Têxteis de Blumenau e Brusque após 1970: a financeirização e os novos espaços de acumulação. Dissertação de Mestrado. Unicamp/IE. 2012.

KARSTEN. [Site da empresa que apresenta seu histórico]. Disponível em http://www.karsten.com.br/institucional\#historico. Acesso em 20 de junho de 2014.

KUEHNRICH, R. Teka: minhas recordações. Livraria Acadêmica. Blumenau, 1995.

MAMIGONIAN, A. Estudo geográfico das indústrias de Blumenau. Revista Brasileira de Geografia - julho/setembro de 1965.

Brusque: Estudo de geografia urbana e econômica. Álbum do Centenário de Brusque (1860). Edição da Sociedade Amigos de Brusque, 1960.

MELLO, J.M.C. (1982) O capitalismo tardio: contribuição à revisão crítica da formação e do desenvolvimento da economia brasileira. Unicamp. Campinas, 1998.

O BANCO Inco e sua contribuição, jornal O Vale do Itajaí: Lavoura, Indústria e Comércio. Centenário de Blumenau, 2 de setembro de 1950, [S.1: s.n.]

RANGEL, I. Economia brasileira contemporânea. Editora Bienal. São Paulo, 1987.

SANTOS, M. (2005) Da totalidade ao lugar. Edusp. São Paulo, 2008. 
SCHMITZ, S. Planejamento governamental: uma avaliação empírica do Plano de Metas do governo - Plameg (1961-1968). Dissertação de mestrado. UFSC, Centro Socioeconômico. Florianópolis, 1982.

SEYFERTH, G. A colonização alemã no Vale do Itajaí-Mirim: um estudo de desenvolvimento econômico. Editora Movimento. Brusque (SC), 1974.

SILVA, M.A. O processo de Industrialização no sul do Brasil. Cadernos Geográficos. Publicação do Departamento de Geociências - CFH-UFSC. Florianópolis, n. 15, maio de 2006.

SILVA, S. (1973) Expansão cafeeira e origens da indústria no Brasil. Alfa -Omega. São Paulo, 1986.

SINGER, P. (1968). Desenvolvimento econômico e evolução urbana. S. Paulo, 2 edição, Cap. 3 - Blumenau. Companhia Editora Nacional, 1977.

STEIN, S. (1957). Origens e evolução da indústria têxtil no Brasil - 18501950. Editora Campus. Rio de Janeiro, 1979.

TAVARES, M. C. (1974) Acumulação de capital e Industrialização no Brasil. 30 anos de economia. Campinas, SP. Unicamp - IE, 1998.

TEKA, 85 anos tecendo uma história de sucesso. Blumenau, 2012.

TEKA comemora seus primeiros 50 anos trabalhando para os próximos cinquenta, Revista comemorativa Teka. [S.l: s.n.]. Não paginado.

THEIS, I. O processo de acumulação em Blumenau. In: Theis, I.; Mattedi, M.A.; Tomio, F. (Org). Nosso passado (in) comum. Editora da Furb. Blumenau, 2000.

TOMIO, F. Breve história da burguesia industrial têxtil blumenauense (constituição, ação política e organizações de classe). In: Theis, I.; Mattedi, M.A.; Tomio F (Org). Nosso passado (in) comum. Editora da Furb. Blumenau, 2000. 